Europe's Journal of Psychology 2/2010, pp. 11-31

www.ejop.org

\title{
Personality as moderator of the relationship between communication and couple stability
}

\section{Ariane Lazaridès}

University of Quebec in Montreal, Quebec, Canada

\section{Claude Bélanger}

University of Quebec in Montreal, McGill University and Douglas Research Center, Montreal, Quebec, Canada

\section{Stéphane Sabourin}

Laval University, Sainte-Foy, Quebec, Canada

\begin{abstract}
In this longitudinal study, we examined the moderating role of personality in the relationship between communication behaviors (withdrawal, dominance, criticism, support, and problem solving) and couple stability. At Time 1, 135 couples completed the NEO Five-Factor Inventory and the Dyadic Adjustment Scale. These couples were also videotaped during a 15-minute problem-solving discussion. Approximately 2.5 years later, these same couples were contacted to assess their relationship status - intact, or separated or divorced. Results show that women's Time 1 extraversion moderates the relationship between couple stability and men's withdrawal and problem solving. Men's neuroticism moderates the relationship between women's problem solving and couple stability. Men's agreeableness moderates the relationship between women's withdrawal and couple stability.
\end{abstract}

Keywords: couples, personality, communication, behaviors, stability, observation. 


\section{Background}

Couple relationships have long been an object of interest for psychologists. However, given the high divorce and separation rates that currently prevail as well as their consequences on individuals, their families and society at large (Ambert, 2005), understanding the processes that lead to couple disruption has taken a new significance and the potential to impact a greater number of people.

Observation of marital interaction has been used by a few research teams to try to pinpoint factors impacting marital outcomes, whether they be marital satisfaction measures or marital stability. While we cannot assume that marital satisfaction and stability are affected in the same manner by different variables, they are clearly related (separation and divorce imply some level of dissatisfaction with the relationship, although dissatisfaction does not necessarily lead to divorce), and most variables have effects of the same valence for both (Karney \& Bradbury, 1995). Research on predictors of marital satisfaction can thus give hints about variables significantly related to marital stability.

Couple interactions have been used to predict whether a couple will separate (Cohan \& Bradbury, 1997; Gottman, 1994; Karney \& Bradbury, 1995; Matthews, Wickrama, \& Conger, 1996). Reciprocation of aversive, or negative, behaviors (e.g. criticism) (Filsinger \& Thoma, 1988; Gottman, 1994) and, interestingly, of rewarding, or positive, behaviors (e.g., agreement) (Filsinger \& Thoma, 1988) has been linked to decreased stability. Whereas the link between reciprocation of negative behaviors and instability intuitively makes sense, it seems surprising that reciprocation of positive behaviors would also be associated with separation. In couples who present a high level of reciprocation of positive behaviors, positive behaviors are more often emitted as a form of payment for a previous positive behavior. It seems that when behaviors are emitted according to a strict reciprocation model, couples are less stable than when there is more flexibility and reciprocation takes place over the long run.

Affects have also been used to predict couple dissolution. Emotions have been found to partially explain the association between social support behaviors and later couple dissolution (Sullivan \& al., 2010). Gottman and his colleagues (Gottman, Coan, Carrere, \& Swanson, 1998) reported that it was possible to predict which couples would divorce over a 6-year period with $83 \%$ accuracy by observing affects expressed during the first three minutes of a session of marital conflict resolution. Predictably, couples that remained stable over this 6-year period manifested more positive affect and less negative affect than couples that would eventually divorce. 
Gottman also found that couples that divorced earlier in their marriage tended to have an affective style characterized by high levels of conflicts and expressed negativity, while couples that divorced later were characterized by high levels of neutral affect - essentially an absence of expressed affect (Gottman \& Levenson, 2002). However, these studies have been subjected to methodological and conceptual criticism (DeKay, Greeno, \& Houck, 2002; Heyman \& Slep, 2001; Stanley, Bradbury, \& Markman, 2000) and have in some cases failed to be replicated (Kim, Capaldi, \& Crosby, 2007). Few other studies have examined the impact of affect on couple stability. Among them, Cohan and Bradbury (1997) found that husband's humor, in the context of major life events, had a negative association with stability. Another study (Rogge, Bradbury, Hahlweg, Engl, \& Thurmaier, 2006) found that hostility of both spouses predicted couple instability over a 5-year period.

Couple relationships feature a complex interplay between the interactions of the two partners and their respective intrapersonal characteristics. In particular, personality is a factor that has been studied frequently in conjunction with close relationships (Cooper \& Sheldon, 2002). In the metaanalysis by Karney and Bradbury (1995), in which they analyzed 115 longitudinal studies of marital outcomes (stability and marital satisfaction), they found that several personality characteristics predicted marital stability. Most of them were factors from the Five-Factor Model of personality (McCrae \& Costa, 1987), which is perhaps the current most prominent model of personality. Its five factors are the following: neuroticism, extraversion, agreeableness, conscientiousness, and openness to experience. In the metaanalysis by Karney and Bradbury (1995), agreeableness and conscientiousness of both genders were positively associated with stability. The case of extraversion and openness is mitigated: few studies found a relationship between these traits and marital stability, and results were inconsistent among them (Donnellan, Conger, \& Bryant, 2004; Watson, Hubbard, \& Wiese, 2000). Neuroticism in both genders was negatively associated with stability. Remarkably, neuroticism was the single variable most negatively related to marital stability for women, and was second only to parental divorce for men. Clearly, personality does play a role in marital stability.

The inconsistencies in the separate bodies of research about couple outcomes and behaviors on the one hand, and personality on the other hand, lead us to believe that more complex models are required to better understand how these variables are related. Little is known about how personality could exert its influence on marital outcomes. However, we can suppose that since personality is a tendency to react in consistent patterns (behavioral, cognitive, or affective) across situations (Pervin, Cervone, \& John, 2005), it is likely to affect how one tends to react to behaviors from the partner (Sullivan, 1997) and as such, is likely to play a role in couple interactions. 
One way to integrate personality and behaviors as predictors of marital satisfaction, is a mediational model in which personality exerts its influence on marital satisfaction through partner interactions. Karney and Bradbury (1995) proposed such a model as part of a larger vulnerability-stress-adaptation model to account for changes in marital satisfaction. Other studies found evidence of a mediation relationship between personality, behaviors and marital outcomes (Caughlin, Huston, \& Houts, 2000; Donnellan et al., 2004). In particular, both these studies found that the relationship between neuroticism and decreased marital satisfaction was mediated by marital interactions high in hostility and low in warmth. Donnellan et al. (2004) also found that the relationships between agreeableness of both genders and marital satisfaction were mediated by marital interactions, as well as that between wives' openness and marital satisfaction.

Another way, never explored as far as we know, in which personality and behaviors could be combined, is in a moderational model that posits that behaviors from one partner are differentially related to marital stability according to the other partner's personality. For example, criticism could have a very different impact on a person high on neuroticism, who tends to get easily angry, hostile or anxious, than on somebody who is even-tempered and tends to experience positive affect. In the same manner, the likely impulsiveness of the high-neuroticism person could mean that they would react in a different way than their low-neuroticism counterpart, evoking a different reaction from their partner, and so on. This model gives a different but complementary point of view from which to understand the interaction between personality and behavior.

In this study, we will examine how verbal (e.g. criticizing) and non verbal (e.g. looking away) communication behaviors manifested by one partners interact with the personality of the other partner to influence couple stability. As a preliminary step, we will start by examining the relationship between communication behaviors and couple stability, and between personality and stability. We will then investigate the potential moderator role of personality in the relationship between communication behaviors and couple stability.

Method

Participants

The original Time 1 sample included 315 French-speaking Canadian heterosexual couples from Quebec. The subsample used for the current study comprises 127 
women and 116 men from 135 different couples who could be contacted, and accepted to participate in the second phase of the study, 2.5 years later. Eighty-two couples $(60.7 \%$ of the sample) were intact, and both members of these couples participated at time 2. Fifty-three couples (39.3\%) of the sample were separated or divorced; eight women and 19 men from those 53 couples declined participation.

At Time 1, 59 (43.7\%) of these couples were married, and 76 (56.3\%) were cohabiting. Cohabitation is widely accepted in Quebec, with about $35 \%$ of all couples cohabiting in 2006 (Statistics Canada, 2007). The proportion of cohabiting couples in our sample is higher, perhaps because our participants are French-speaking and have more formal education than average, two characteristics that are associated, in Quebec, with a higher likelihood of cohabitation (Milan, 2003). The couples in our sample had been living together for an average of 7.7 (SD $=7.68$ ) years. Couples had an average of 1.00 child from their current relationship $(S D=1.29$ ), and individuals had on average .32 children from previous relationship (SD = .83). The mean age of women was 33.8 years $(S D=9.01)$, with 15.36 years of formal education (SD = 3.05). The mean age of men was 36.34 years, with 15.84 years of formal education ( $S D=3.64)$. Mean annual income was $\$ 21,418 \mathrm{CDN}(S D=15,287$ ) for women and $\$ 36,656 \mathrm{CDN}(S D=22,450)$ for men.

Couples in which men had more education $(t(133)=2.298, p=.023$ ) or women had a higher income $(t(133)=1.978, p=.05)$ were less likely to be separated. Marital status at Time 1 was not linked significantly to separation or divorce.

\section{Procedure}

These couples were recruited in the community through newspapers, television and radio. At both stages of the study, they completed self-report questionnaires (see description below). At stage 1, they were also videotaped during a 15-minute conflict resolution discussion whose topic was chosen based on the partners' answers to the Potential Problem Checklist (Patterson, 1976).

\section{Measures}

Dyadic adjustment. The Dyadic Adjustment Scale (DAS; Spanier, 1976, translated into French by Baillargeon, Dubois, \& Marineau, 1986) is a self-report measure of marital adjustment. Its 32 items yield a global score which is used as a measure of dyadic adjustment as perceived by the individual. A score of 100 or above is usually interpreted as indicating good adjustment. In our sample, $60.0 \%$ of women and $68.9 \%$ of men were adjusted at Time 1 . The French version used for this study has 
satisfying psychometric properties (Baillargeon et al., 1986; Sabourin, Lussier, Laplante, \& Wright, 1990). In the current study, Cronbach's alpha for this questionnaire was .84 .

Conflict sources. The Potential Problem Checklist (Patterson, 1976, translated into French and modified by Bourgeois, Sabourin, \& Wright, 1990) enumerates 16 topics that can be a source of conflicts for couples, and asks the respondent to rate, on a 7-point Likert scale, to what degree they and their partner agree about each topic.

Personality. The NEO Five-Factor Inventory is a shortened version of the NEO Personality Inventory-Revised (Costa \& McCrae, 1992). It comprises 60 statements that are rated on a 5-point Likert scale, ranging from "strongly disagree" to "strongly agree", according to the extent to which the respondent believes the statement describes him- or herself. The inventory yields scores on five subscales: neuroticism (defined as anxiety, depression, hostility, impulsiveness, self-consciousness, and vulnerability); extraversion (defined as warmth, gregariousness, assertiveness, activity, excitement seeking, and positive emotions); openness (defined as openness to fantasy, aesthetics, feelings, actions, ideas, and values); agreeableness (defined as altruism, compliance, modesty, straightforwardness, tender-mindedness, and trust); and conscientiousness (defined as achievement striving, competence, deliberation, dutifulness, order, and self-discipline). The scores are transformed in $T$ scores with a mean of 50 and a standard deviation of 10. For this study, alpha coefficients ranged from .62 to .80 .

Communication behaviors. The Global Couple Interaction Coding System (GCICS; Bélanger, Dulude, Sabourin, \& Wright, 1993) is a macroanalytic marital coding system that measures five dimensions of couples' problem-solving interactions: (1) withdrawal/avoidance : withdrawal from discussion, avoidant non-verbal behavior; (2) dominance: control and direction of the discussion; (3) criticism/attack/conflict: criticism, blame, threat, non-verbal display of hostility, negative mind-reading and negative escalation; (4) support and validation: listening, validation and reinforcement of partner's statements, verbally or non-verbally; (5) problem solving : acknowledgement of the existence of a problem and work towards its resolution. Each dimension includes verbal as well as nonverbal behaviors.

For this study, the couples' 15-minute discussions were coded by two graduate students in psychology who received training in coding problem-solving interactions with this instrument. The discussions were divided into three 5-minute segments. For each of the five dimensions, each partner was given a score on a 4-point scale ranging from "not displayed" to "strongly displayed" according to the frequency, 
intensity and duration of the behaviors displayed during each of the three segments. The scores given by a coder for the three segments were then averaged to yield the global score for that dimension. The final score for each dimension was the average of the global scores given by the two coders. Intercoder agreement was calculated with intraclass correlation coefficients using the global scores of 25 discussions. The intercoder agreements were .90 for withdrawal, .84 for dominance, .86 for criticism, .75 for support, and .78 for problem-solving behaviors, with an average of .83, which denotes nearly perfect agreement, according to Bech and Clemmesen (1983).

Couple stability. Couple stability is a binary variable representing the status (separated/divorced, coded 0, or together, coded 1) of the couple at time 2. It was measured by asking partners, when contacted to participate in the second phase of our study, whether they were still together.

Results

Means and standard deviations for dyadic adjustment, personality, and communication behaviors at Time 1 are presented in Table 1. We verified whether men and women differed on these variables, using gender as a repeated measure because the scores of men and women were expected to be correlated. Men scored significantly higher on dyadic adjustment $(t(134)=3.33, p=.001$, effect size $d$ $=.21)$ and withdrawal $(t(134)=2.03, p=.04, d=.18)$, and significantly lower on neuroticism and criticism $(t(134)=3.33, p=.001, d=.39$ and $t(134)=3.44, p=.001, d$ $=.23$, respectively).

Table 1: Means and standard deviations for Time 1 variables by gender

\begin{tabular}{lcccc}
\hline & \multicolumn{2}{c}{ Women } & \multicolumn{2}{c}{ Men } \\
\cline { 2 - 5 } & $M$ & SD & $107.68^{* * *}$ & 18.40 \\
\hline Dyadic Adjustment Scale & 103.42 & 21.48 & & \\
\hline NEO-FFI subscales & & & $47.73^{* * *}$ & 8.77 \\
Neuroticism & 51.27 & 9.34 & 51.57 & 10.32 \\
Extraversion & 49.47 & 10.57 & 50.68 & 10.47 \\
Openness & 50.05 & 10.33 & 49.97 & 10.00 \\
Agreeableness & 50.42 & 10.60 & 51.22 & 9.97 \\
Conscientiousness & 48.99 & 11.00 & & \\
\hline Communication behaviors & & & $.56^{*}$ & .57 \\
Withdrawal & .46 & .52 & .74 & .58 \\
Dominance & .75 & .52 &
\end{tabular}


Criticism

Support

Problem solving
.62

.53

.58
.59

.36

.33
$49^{* * *}$

.51

.55
.53

35

.35

Note: $\mathrm{n}=135$. Means accompanied by asterisks indicate that a significant difference was found between the means of men and women for this variable. All $p$ values for two-tailed tests.

$* \mathrm{p}<.05,{ }^{* * *} \mathrm{p}<.001$

Correlations between Time 1 variables and couple stability

We then examined how Time 1 dyadic adjustment, communication behaviors and personality were related to couple stability. Couple stability was coded as a dummy variable with 0 standing for separated/divorced couples and 1 for intact couples. Male and female dyadic adjustment were correlated with stability $(r(133)=.355, p=$ .000 and $r(133)=.402, p=.000$, respectively). Given the correlation between dyadic adjustment and stability, we then used each gender's dyadic adjustment as a covariable when computing the correlations between the other variables for that gender (personality and communication behaviors) and stability. The only Time 1 variable correlated to stability was female support $(r(133)=-.17, p=.05)$. The weakness of many of the associations between communication behaviors and stability could be the result of the existence of a moderator variable (Baron \& Kenny, 1986), which was hypothesized to be personality. If this hypothesis were right, the associations between Time 1 behaviors and Time 2 stability, which were low when we considered all levels of personality traits in the partial correlations, would become stronger at different levels of personality traits. This is the hypothesis that we tested next.

Moderation by personality of one partner of the relationship between communication behaviors of the other partner and couple stability

We examined if and how personality of one partner moderated the relation between communication behaviors of the other partner and couple stability. According to Baron \& Kenny (1986), a moderator is a variable that changes the direction and/or strength of the relation between an independent or predictor variable and a dependent or criterion variable. Kraemer et al. (2002) add that a moderator also has to preexist the independent variable. In our case, we wanted to verify if communication behaviors emitted by one of the partners were differently related to couple stability depending on the personality traits of the other partner. For each personality factor of partner A, we performed logistic regressions of time-2 stability using the following predictors: the mean of time- 1 dyadic adjustment of both 
partners as the first block, the $z$ values of the personality factor score of partner A and of the communication behavior score of partner $B$ as the second block, and the product of the $z$ values of the personality factor of partner $A$ and communication behavior of partner $B$ as the third block, following the procedure suggested by Baron and Kenny (1986). Note that the requirement for the moderator to not be correlated to either the independent variables (here, communication behaviors) or the dependent variable (marital stability) concerns not so much the significance of the correlation as its strength, or absolute value (Jaccard, Turrisi, \& Wan, 1990). In this study, none of these correlations were above .29. We can thus safely assume that neither the independent variables nor the moderators, taken alone, are sufficient to explain the dependent variable's variance and we have been able to successfully run moderation analyses. The requirement that the moderator should be present before the independent variable is also met, since personality of either partner, as a stable characteristic, preexists communication behaviors from the other partner.

We plotted the significant interactions at three levels of the moderator $(z=-1, z=0$, and $z=1$ ). For each of the three levels of the moderator, we calculated the value of the regression equation at two levels of the predictor $(z=-1$ and $z=1)$, giving us three lines representing the interaction. We also calculated the region of significance of the relationship between the predictor and the dependent variable, that is, at what values of the personality trait (moderator variable) the relationship between the behavior (predictor) and couple stability (dependent variable) became significant. We tested for significance up to +/- 3 SD. It is noteworthy that the very fact that there is a significant interaction between behavior and personality trait indicates that the relationship between behavior and couple stability varies significantly across the range of values of the personality trait (Jaccard et al., 1990), i.e., regardless of the region of significance, there exists two values of the moderator variable for which the relationship between predictor and dependent variable differs significantly.

Figure 1 (and associated results in Table 2) show that men's neuroticism moderates the relationship between women's problem solving and couple stability, such that an increase in men's neuroticism is associated with a more positive relationship between women's problem solving and couple stability. The relationship between women's problem solving and couple stability becomes significant when men's neuroticism is greater than 2.0 SD above mean. 
Figure 1: Relationship between women's problem solving and couple stability according to men's neuroticism level

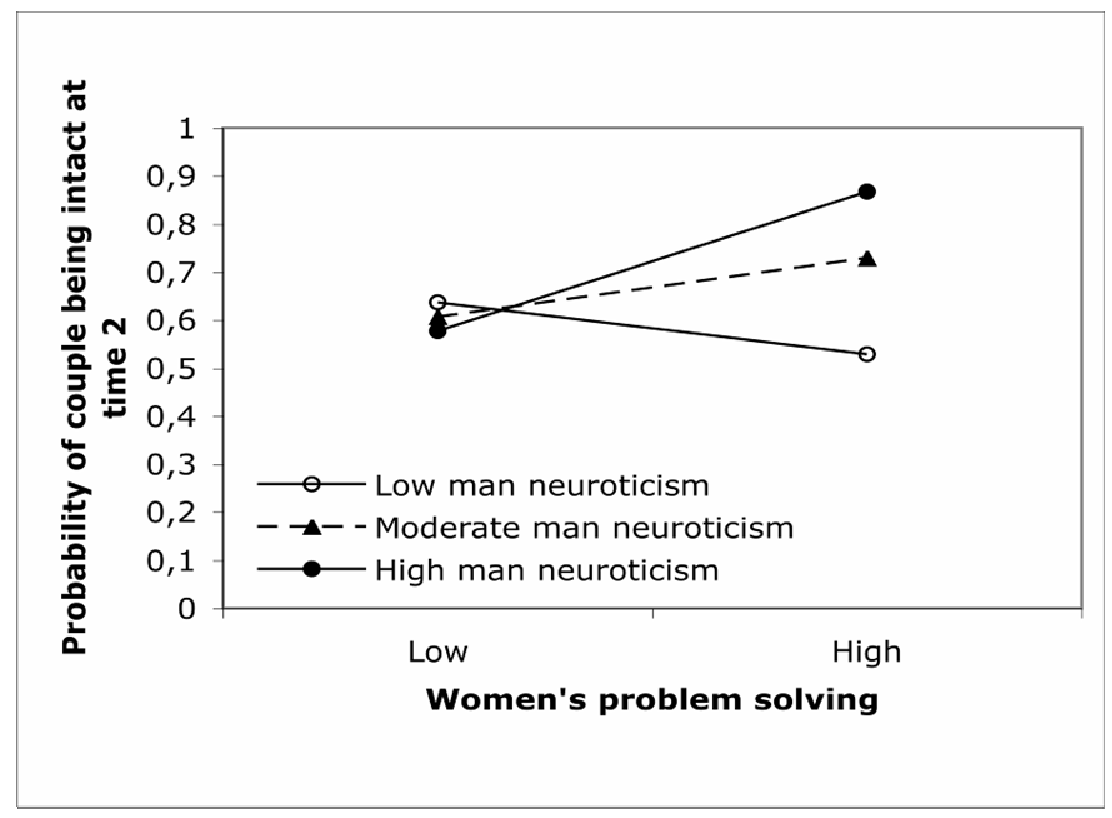

Table 2: Logistic regression analysis of couple stability on the interaction between men's neuroticism and women's problem solving

\begin{tabular}{lccccc}
\hline Predictor & B & SE B & Wald's $\chi^{2}$ & $p$ & Odds ratio \\
\hline Average of T1 DAS & .06 & .01 & 19.44 & .00 & 1.06 \\
Men's neuroticism & .38 & .26 & 2.18 & .14 & 1.46 \\
Women's problem solving & .28 & .25 & 1.28 & .26 & 1.32 \\
$\begin{array}{l}\text { Men's neuroticism x women's } \\
\text { problem solving }\end{array}$ & .50 & .25 & 3.95 & .04 & 1.65 \\
Constant & -5.30 & 1.33 & 15.84 & .00 & .005 \\
\hline
\end{tabular}

Note: Model's $\chi^{2}=28.76, d f=4, p=.00$. Wald's $d f=1$ for all predictors. Interaction term's Cox \& Snell $R^{2}$ change $=0.025$.

Figure 2 and Table 3 show that women's extraversion moderates the relationship between men's problem solving and couple stability. A greater female extraversion is associated with a more negative (or less positive) relationship between men's problem solving and couple stability. The relationship between men's problem solving and couple stability is significant when women's extraversion is lower than 1.1 SD below mean or higher than 1.3 SD above mean. 
Figure 2: Relationship between men's problem solving and couple stability according to women's extraversion level.

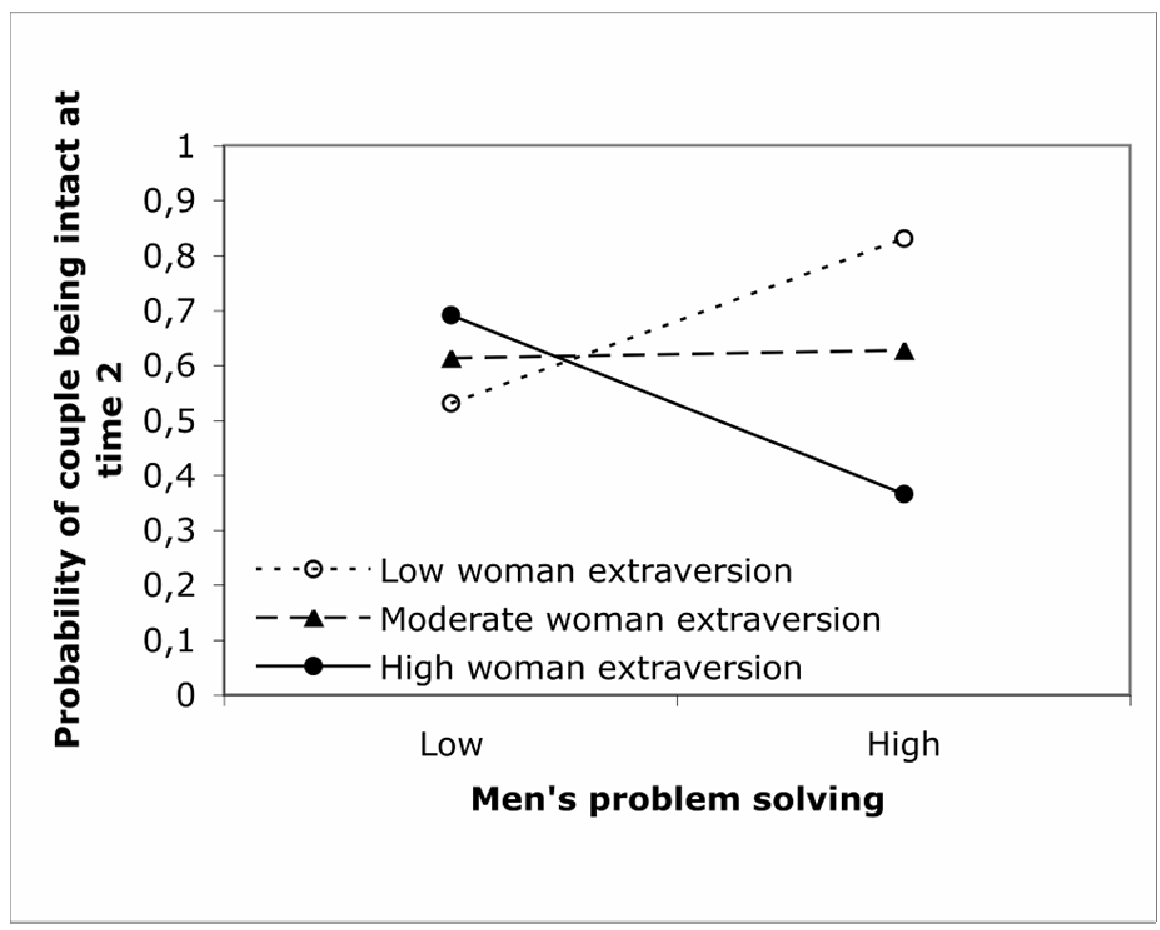

Table 3: Logistic regression analysis of couple stability on the interaction between women's extraversion and men's problem solving

\begin{tabular}{lccccc}
\hline Predictor & B & SE B & Wald's $\chi^{2}$ & $p$ & Odds ratio \\
\hline Average of T1 DAS & .06 & .01 & 19.74 & .00 & 1.06 \\
Women's extraversion & -.36 & .22 & 2.75 & .10 & .70 \\
Men's problem solving & .03 & .24 & 0.13 & .91 & 1.03 \\
Women's extraversion x men's problem & -.71 & .30 & 5.47 & .02 & .49 \\
solving & -6.06 & 1.46 & 17.11 & .00 & .002 \\
Constant & & & & & \\
\hline
\end{tabular}

Note: Model's $\chi^{2}=32.11, \mathrm{df}=4, \mathrm{p}=.00$. Wald's $\mathrm{df}=1$ for all predictors. Interaction term's Cox \& Snell $R^{2}$ change $=0.037$.

In Figure 3 and Table 4, we see that women's extraversion moderates the relationship between men's withdrawal and stability. The figure shows that an increase in women's extraversion was associated with a more positive (or less negative) relationship between men's withdrawal and couple stability. The relationship between men's withdrawal and couple stability becomes significant when women's extraversion is lower than 0.4 SD below mean or higher than 1.2 SD above mean. 
Figure 3: Relationship between men's withdrawal and couple stability according to women's extraversion level

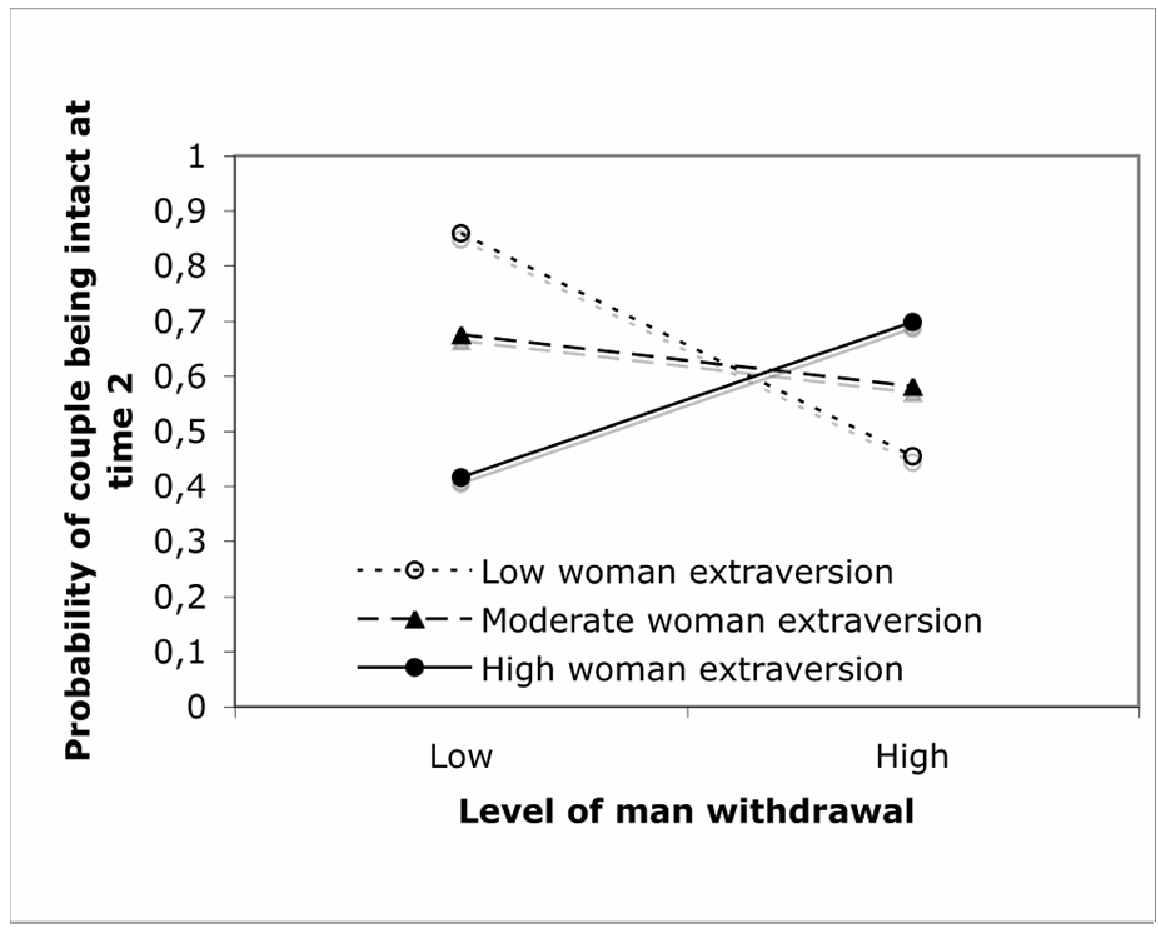

Table 4: Logistic regression analysis of couple stability on the interaction between women's extraversion and men's withdrawal

\begin{tabular}{lccccc}
\hline Predictor & B & SE B & Wald's $\chi^{2}$ & $p$ & Odds ratio \\
\hline Average of TI DAS & .06 & .01 & 18.29 & .00 & 1.06 \\
Women's extraversion & -.28 & .22 & 1.59 & .21 & .70 \\
Men's withdrawal & -.20 & .22 & 0.82 & .36 & 1.03 \\
Women's extraversion $\times$ men's withdrawal & .79 & .27 & 8.53 & .004 & .49 \\
Constant & -5.80 & 1.47 & 15.60 & .00 & .002 \\
\hline
\end{tabular}

Note: Model's $\chi^{2}=37.15, \mathrm{df}=4, \mathrm{p}=.00$. Wald's $\mathrm{df}=1$ for all predictors. Interaction term's Cox \& Snell $R^{2}$ change $=0.064$.

Figure 4 and Table 5 show that there is an interaction between women's withdrawal and men's agreeableness in predicting couple stability, such that an increase in men's agreeableness was associated with a more negative, or less positive, relationship between women's withdrawal and couple stability. The relationship between women's withdrawal and couple stability is significant when men's agreeableness is lower than 1.8 SD below mean or higher than 0.6 SD above mean. 
Figure 4: Relationship between women's withdrawal and couple stability according to men's agreeableness level.

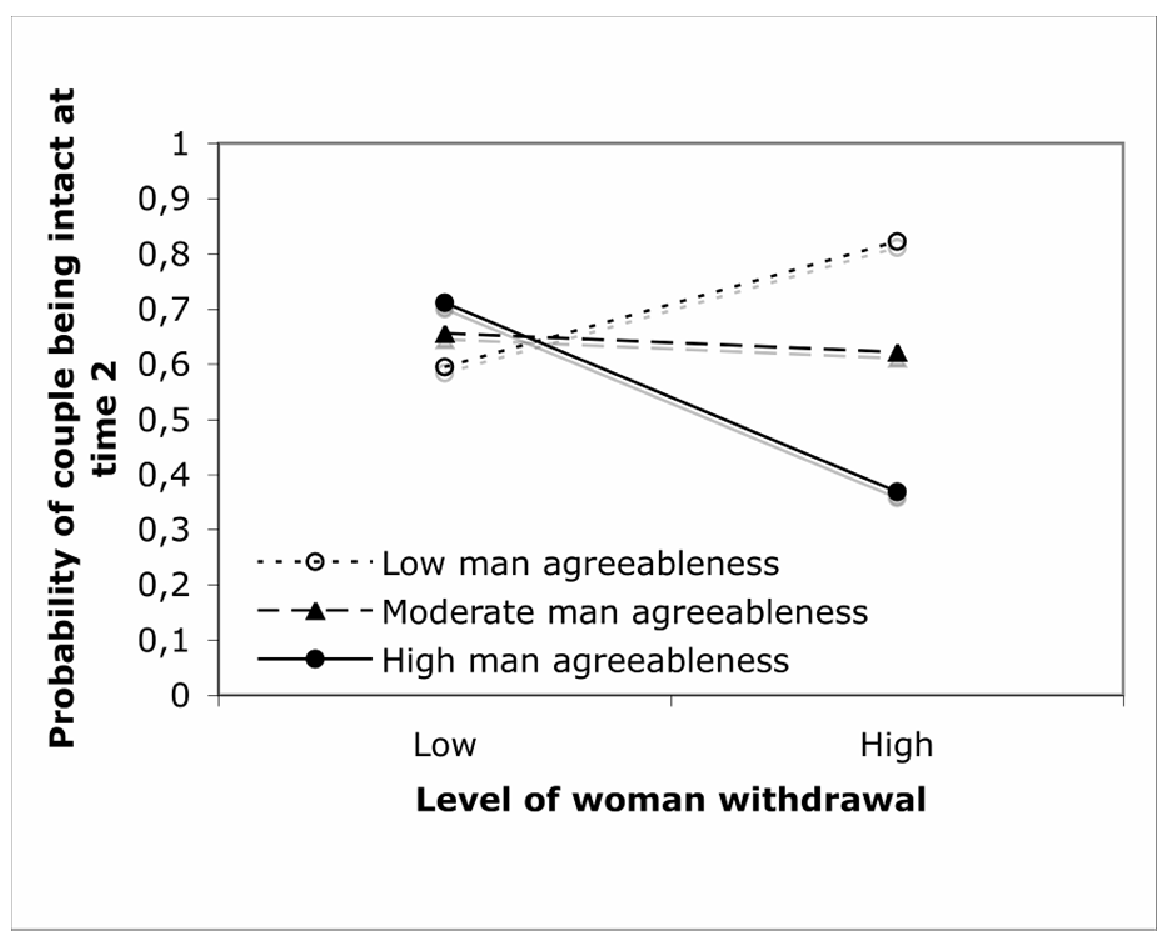

Table 5: Results of the regression of couple stability on the interaction between men's agreeableness and women's withdrawal

\begin{tabular}{lccccc}
\hline Predictor & B & SE B & Wald's $\chi^{2}$ & $p$ & Odds ratio \\
\hline Average of T1 DAS & .06 & .01 & 18.29 & .00 & 1.07 \\
Men's agreeableness & -.39 & .23 & 1.59 & .09 & .68 \\
Women's withdrawal & -.07 & .20 & 0.82 & .72 & .93 \\
Men's agreeableness $\times$ women's & .65 & .28 & 8.53 & .02 & .52 \\
$\begin{array}{l}\text { withdrawal } \\
\text { Constant }\end{array}$ & -6.50 & 1.47 & 15.60 & .00 & .002 \\
\hline
\end{tabular}

Note: Model's $\chi^{2}=32.66, \mathrm{df}=4, \mathrm{p}=.00$. Wald's $\mathrm{df}=1$ for all predictors. Interaction term's Cox \& Snell $\mathrm{R}^{2}$ change $=0.034$.

\section{Discussion}

In this research, we have explored the moderator role of personality in the relationship between Time 1 communication behaviors and couple stability 2.5 years later. We have found that women's conscientiousness and extraversion, and men's 
agreeableness all play a moderator role in the relationship between communication behaviors of their partners and couple stability.

We found that men's neuroticism moderates the relationship between women's problem solving and couple stability. Neuroticism and its elevated levels of negative emotions has been associated with poor choice of problem-solving strategies, especially when the individual high in neuroticism is in conflict with someone close to them (DeLongis \& Holtzman, 2005). However, the moderating effect of women's problem solving behaviors on the relationship between men's neuroticism and couple stability seems to indicate that adequate problem solving behaviors displayed by women compensate for high-neuroticism men's poor problem-solving skills.

Women's extraversion also moderates the relationship between men's problem solving and couple stability. For low-extraversion women, the relationship between men's problem solving and couple stability is positive. Apparently, the relative passivity and nonassertive behavior of these women is well complemented by a high level of problem-solving behaviors on their partner's part. As women's extraversion increases, the relationship between men's problem solving and couple stability becomes more negative. This result is consistent with previous research (Wood \& Bell, 2008) that found that extraversion positively predicted a conflict-resolution style that was assertive, and negatively predicted a conflict-resolution style that was collaborative and accommodating. In other words, extraverted women would tend to force their preferred solution to the conflict upon their partner. It thus seems that the combination of a man who tries to solve relationship problems by finding compromises and a woman who is victory-oriented in her problem solving interactions with her spouse is associated with low couple stability.

Women's extraversion also moderates the relationship between men's withdrawal and stability. The relationship goes from negative at the lower end of the women's extraversion spectrum, to positive at its higher end. In other words, couples with a withdrawn man and a woman low on extraversion are more likely to separate or divorce than couples with a withdrawn man and an extraverted woman, whose complementary behaviors could be contributing to higher couple functioning. Therefore, the extraverted woman would take the conversational space not taken by the withdrawn man, leading to a mutually acceptable interaction style. On the other hand, couples with a low-extraversion woman and a high-withdrawal man could have interactions that are not stimulating to either of the members and they would become detached in the long run. Gottman and Levenson (2002) found that a highly neutral affective style during couple interactions was predictive of divorce 
after a long union. Such could be the case in couples where the woman is low on extraversion and the man is high on withdrawal.

We also found that men's agreeableness moderates the relationship between women's withdrawal and couple stability, such that for low-agreeableness men, the correlation between women's withdrawal and stability is positive, whereas it is neutral in the moderate-agreeableness men group and negative in the highagreeableness men group. In other words, couples with an avoidant woman are less likely to dissolve if the man is low on agreeableness. Highly agreeable men focus on positive relationships and expect reciprocity to their benevolent attitude towards others. It is likely that withdrawn women fail to manifest such an attitude and this could create distress in their partners and eventually, this situation could contribute to a decrease in couple stability. The combination of a man low on agreeableness and a withdrawn woman, on the other hand, seems to be stable. One hypothesis is that they form a subgroup of emotionally disengaged couples where the woman has adopted withdrawal as a tactic against the man's irritability and egocentrism, and this arrangement allows them to go on as a stable, albeit most likely unhappy, couple. It seems that the relationship of agreeableness to couple stability is more complex than previous research would let us suppose and further research is needed to better understand this relationship.

This study shows that a proper assessment of couples must take into account personality as a factor in the impact that partners' behaviors have on relationship functioning, and eventually, on stability of the couple. As this study suggests, clinicians should be aware that personality influences how one perceives the behavior of one's partner, and a proper evaluation must take this influence into account in order to pinpoint with more accuracy those aspects of the conjugal relationship that create distress.

\section{Limitations and conclusion}

The results from this study suggest that the personality of a person does have a moderator role in the relationship between the communication behaviors of this person's partner and couple stability. In other words, one's communication behaviors' influence on stability varies with the personality traits of the partner. In our study, women's conscientiousness and extraversion, as well as male agreeableness, played such a moderator role. This research was the first, as far as we know, to test a moderational model of communication behavior, personality and couple stability. As such, beyond the results obtained, it opens new research questions and invites further exploration of more complex relationships between predictors of marital 
stability. We studied combinations of one type of communication behavior from one partner and one personality trait in the other partner, but it is likely that there are many more combinations that could be examined, involving more traits or other characteristics such as attachment, attributions, life events, etc. Of course, as the complexity of the model grows, so do the costs of testing it, in terms of time, number of participants, etc., but a better understanding of the complexities of couple dynamics cannot dispense with models that have the capability to represent these subtleties. The current study is a step in that direction. Our study also helps to bridge individual differences theories of couple stability with theories focused on behavioral factors, which have long been independently studied.

A limitation to the generality of our results comes from the composition of our sample. Perhaps because of the recruiting procedure which used a free consultation with a couple therapist as an incentive, our sample seems to have a lower dyadic adjustment than that of the samples used for validation. Dyadic adjustment score in our sample was around 105 on average, whereas average is close to 114 in samples used to validate the Dyadic Adjustment Scale and its French translation (Baillargeon et al., 1986; Spanier, 1976). This might explain the very high separation rate of $40 \%$ over 30 months. The fact that most couples in our sample were cohabiting could also have an impact on the separation rate, as cohabiting couples have a higher separation rate than married couples (Ambert, 2005). However, the lower dyadic adjustment also means that this sample is perhaps closer to what would be found in the general population and certainly closer to consulting couples.

It is also noteworthy that the participating couples were not selected according to the length of their union. The influence of personality on stability is not necessarily the same at the beginning of a relationship than after a longer time (Bouchard \& Arseneault, 2005), and our conclusions could have been different if we had used a sample of newlyweds or a sample of mature couples. We know from preliminary analyses of our data that for women, but not for men, dyadic adjustment at time 1 was negatively correlated with length of the relationship. However, marital status was not related to dyadic adjustment for either gender.

It is also possible that the individuals from separated couples who chose to participate in the second stage of our study differed from those who declined in ways that could have affected our results, but we did not find any evidence supporting that hypothesis.

We assessed personality by one self-report measure, which can be subject to social desirability and other biases. Ideally, personality would be assessed by behavioral 
observation, but this would be a much more resource-consuming procedure than the one used in this study. We also assessed personality at one point in time, as personality is purported to be quite stable (Roberts \& DelVecchio, 2000), and as such we did not expect to measure much change over a 2.5 year period. The fact that personality was measured by way of a self-report measure but behaviors were observed adds to the strength of the results presented here, as shared measure variance is eliminated.

We chose to use the standard alpha level throughout the study, thus decreasing the risk of type-ll errors. In the context of an exploratory study such as the current one, it makes sense to choose a lower risk of making type-ll errors. Imposing an overly demanding alpha level, at this stage of research, could have the effect of eliminating potentially interesting research avenues. We have thus chosen to favor exploration of new avenues at the expense of a more conservative alpha level. As discussed by Kraemer \& al. (2002), such a strategy is useful to "foster stronger hypothesis-testing studies and to provide the background information necessary to design such powerful studies."

More research is certainly necessary to get a clearer picture of the relationship between communication behaviors, personality, their interaction and couple stability. However, the results reported here are an indication that the interplay between these factors could be worth considering when assessing couple difficulties. The actual behaviors manifested during couple interactions are processed through filters (such as personality) at both ends of the communication and these filters' role could be important to grasp the dynamics of distressed as well as nondistressed couples.

\section{References}

Ambert, A.-M. (2005). Divorce: Facts, Causes, and Consequences. Ottawa, Canada: Vanier Institute of the Family.

Baillargeon, J., Dubois, G., \& Marineau, R. (1986). Traduction française de l'Échelle d'ajustement dyadique [A french translation of the Dyadic Adjustment Scale]. Revue canadienne des sciences du comportement, 18, 24-34.

Baron, R. M. \& Kenny, D. A. (1986). The moderator-mediator variable distinction in social psychological research: conceptual, strategic, and statistical considerations. Journal of Personality \& Social Psychology, 51, 1173-1182. 
Bech, P. \& Clemmesen, L. (1983). The diagnosis of depression: 20 years later. Acta Psychiatrica Scandinavica, 68, 9-30.

Bélanger, C., Dulude, D., Sabourin, S., \& Wright, J. (1993). Validation préliminaire d'un système global de cotation des interactions conjugales. Revue canadienne des sciences du comportement, 25, 483-498.

Bouchard, G. \& Arseneault, J.-E. (2005). Length of union as a moderator of the relationship between personality and dyadic adjustment. Personality and Individual Differences, 39, 1407-1417.

Bourgeois, L., Sabourin, S., \& Wright, J. (1990). Predictive validity of therapeutic alliance in group marital therapy. Journal of Consulting and Clinical Psychology, 58, 608-613.

Caughlin, J. P., Huston, T. L., \& Houts, R. M. (2000). How does personality matter in marriage? An examination of trait anxiety, interpersonal negativity, and marital satisfaction. Journal of Personality and Social Psychology, 78, 326-336.

Cohan, C. L. \& Bradbury, T. N. (1997). Negative life events, marital interaction, and the longitudinal course of newlywed marriage. Journal of Personality and Social Psychology, 73, 114-128.

Cooper, M. L. \& Sheldon, M. S. (2002). Seventy years of research on personality and close relationships: Substantive and methodological trends over time. Journal of Personality, 70, 783-812.

Costa, P. T. \& McCrae, R. R. (1992). Revised NEO Personality Inventory (NEO PI-R) and NEO Five-Factor Inventory (NEO-FFI) professional manual. Odessa, FL: Psychological Assessment Resources.

DeKay, M. L., Greeno, C. G., \& Houck, P. R. (2002). Searching for a two-factor model of marriage duration: Commentary on Gottman and Levenson. Family Process, 41 , 97-103. DeLongis, A. \& Holtzman, S. (2005). Coping in context: The role of stress, social support, and personality in coping. Journal of Personality, 73, 1-24.

Donnellan, M. B., Conger, R. D., \& Bryant, C. M. (2004). The Big Five and enduring marriages. Journal of Research in Personality, 38, 481-504.

Filsinger, E. E. \& Thoma, S. J. (1988). Behavioral antecedents of relationship stability and adjustment: A five-year longitudinal study. Journal of Marriage \& the Family, 50, 785-795. 
Gottman, J. M., Coan, J., Carrere, S., \& Swanson, C. (1998). Predicting marital happiness and stability from newlywed interactions. Journal of Marriage \& the Family, 60, 5-22.

Gottman, J. M. (1994). What predicts divorce? The relationship between marital processes and marital outcomes. Hillsdale, NJ: Lawrence Erlbaum Associates, Inc.

Gottman, J. M. \& Levenson, R. W. (2002). A two-factor model for predicting when a couple will divorce: Exploratory analyses using 14-year longitudinal data. Family Process, $41,83-96$.

Heyman, R. E. \& Slep, A. M. S. (2001). The hazards of predicting divorce without crossvalidation. Journal of Marriage \& the Family, 63, 473-479.

Jaccard, J., Turrisi, R., \& Wan, C. K. (1990). Interaction effects in multiple regression (72). Beverly Hills, CA: Sage.

Karney, B. R. \& Bradbury, T. N. (1995). The longitudinal course of marital quality and stability: A review of theory, methods, and research. Psychological Bulletin, 118, 3-34.

Kim, H. K., Capaldi, D. M., \& Crosby, L. (2007). Generalizability of Gottman and Colleagues' Affective Process Models of Couples' Relationship Outcomes. Journal of Marriage \& Family, 69, 55-72.

Kraemer, H. C., Wilson, T., Fairburn, C. G., Agras, W. S. (2002). Mediators and moderators of treatment effects in randomized clinical trials. Archives of General Psychiatry, 59, 883.

Matthews, L. S., Wickrama, K. A. S., \& Conger, R. D. (1996). Predicting marital instability from spouse and observer reports of marital interaction. Journal of Marriage \& the Family, 58, 641-655.

McCrae, R. R. \& Costa, P. T. (1987). Validation of the five-factor model of personality across instruments and observers. Journal of Personality and Social Psychology, 52, 81-90.

Milan, A. (2003). Would you live common-law? Canadian Social Trends, 70, 2-6. Patterson, G. R. (1976). Some procedures for assessing changes in marital interactions patterns. Oregon Research Institute Bulletin, 16.

Pervin, L. A., Cervone, D., \& John, O. P. (2005). Personality: Theory and Research (9th ed.). Oxford, England: John Wiley \& Sons.

Roberts, B. W. \& DelVecchio, W. F. (2000). The rank-order consistency of personality traits 
from childhood to old age: A quantitative review of longitudinal studies. Psychological Bulletin, 126, 3-25.

Rogge, R. D., Bradbury, T. N., Hahlweg, K., Engl, J., \& Thurmaier, F. (2006). Predicting Marital Distress and Dissolution: Refining the Two-Factor Hypothesis. Journal of Family Psychology, 20, 156-159.

Sabourin, S., Lussier, Y., Laplante, B., \& Wright, J. (1990). Unidimensional and multidimensional models of dyadic adjustment: A hierarchical reconciliation. Psychological Assessment, 2, 333-337.

Spanier, G. B. (1976). Measuring dyadic adjustment: New scales for assessing the quality of marriage and similar dyads. Journal of Marriage and the Family, 38, 15-28.

Stanley, S. M., Bradbury, T. N., \& Markman, H. J. (2000). Structural flaws in the bridge from basic research on marriage to interventions for couples. Journal of Marriage \& the Family, 62, 256-264.

Sullivan, K. T., Pasch, L. A., Johnson, M. D., \& Bradbury, T. N. (2010). Social support, problem solving, and the longitudinal course of newlywed marriage. Journal of Personality and Social Psychology, 98, 631-644.

Statistics Canada. (2007). Familles comptant un couple selon la présence d'enfants de tous les âges dans les ménages privés, chiffres de 2006, pour le Canada, les provinces et les territoires - Données-échantillon (20\%) [Families consisting of a couple with or without children of all ages in private households, 2006 counts, $20 \%$ sample data.]. Retrieved November 29th, 2007, from http://www12.statcan.ca/english/census06/data/highlights/households/pages/Page.c $\mathrm{m}$ ? Lang $=\mathrm{F} \& \mathrm{GeO}=\mathrm{PR} \&$ Code $=01 \&$ Table $=1$ \&Data $=$ Count \&Age $=1 \&$ StartRec $=1$ \&Sort $=2 \&$ Dis lay=Page

Sullivan, K. T. (1997). Contributions of personality and behavior to change in marital satisfaction. Dissertation Abstracts International: Section B: The Sciences and Engineering, $58,3328$.

Watson, D., Hubbard, B., \& Wiese, D. (2000). General traits of personality and affectivity as predictors of satisfaction in intimate relationships: Evidence from self and partner ratings. Journal of Personality, 68, 413-449.

Wood, V. F. \& Bell, P. A. (2008). Predicting interpersonal conflict resolution styles from personality characteristics. Personality and Individual Differences, 45, 126-131. 


\section{About the authors:}

Dr. Ariane Lazarides completed her Ph.D at the University of Quebec in Montreal, under the direction of Dr. Bélanger. Her primary research interests focus on couple relationships and predictors of couple stability.

Correspondence should be addressed to Dr. Lazarides at: ariane.lazarides@gmail.com.

Dr. Claude Bélanger is a full professor and director of the laboratory for the study of couples at the University of Quebec in Montreal, as well as associate professor in the Psychiatry Department at McGill University and researcher at the Douglas University Mental Health University Institute. His primary research interests include predictors of marital adjustment, problem solving behaviours in couples, and anxiety in relation to marital functioning.

Correspondence should be addressed to Dr. Bélanger at: belanger.claude@uqam.ca.

Dr. Stéphane Sabourin is a full professor and director of the laboratory for the study of couples at Laval University in Quebec city. His primary research interests include predictors of marital adjustment, as well as personality disorders and their relationship to marital functioning.

Correspondence should be addressed to Dr. Sabourin at:

Stephane.Sabourin@psy.ulaval.ca. 